\section{Conducting qualitative interviews with school children in dental research}

\author{
P. Gill, ${ }^{1}$ K. Stewart, ${ }^{2}$ E. Treasure ${ }^{3}$ and B. Chadwick ${ }^{4}$
}

IN BRIEF

- Children have traditionally been excluded from personally participating in research, due to a variety of pragmatic and ethical concerns.

- Where children's personal perspectives are sought, proxy information (even from parents) is often inadequate.

- Interviews, even with young children, can produce unique, detailed and trustworthy accounts, which can be used to improve understanding on a variety of issues.

This paper explores when and how to conduct qualitative research with children in dentistry, using research interviews as a method of data collection. Methodological guidance is also provided, based on research and a recent dental public health study in which 74 children from Years 2 (6-7-year-olds) and 6 (10-11-year-olds) were interviewed about their understanding of and attitudes to food.

\section{INTRODUCTION}

The previous paper in the series ${ }^{1}$ explored the most common methods of data collection used in qualitative research: interviews and focus groups. This paper explores how research interviews can also be used to collect data from children in the appropriate dental studies.

Whilst research involving children in dentistry is extremely common, the majority of this research has been quantitative in nature. Although now used with increasing frequency in dentistry,

\section{QUALITATIVE RESEARCH IN DENTISTRY \\ 1. Qualitative research in dentistry \\ 2. Methods of data collection in qualitative research: interviews and focus groups \\ 3. Conducting qualitative interviews with school children in dental research \\ 4. Analysing and presenting qualitative data}

* Senior Research Fellow, Faculty of Health, Sport and Science, University of Glamorgan, Pontypridd, CF37 1DL; ${ }^{2}$ Research Fellow, Academic Unit of Primary Care, University of Bristol, Bristol, BS8 2AA, ${ }^{3}$ Dean and Professor of Dental Public Health; ${ }^{4}$ Professor of Paediatric Dentistry, School of Dentistry, Dental Health and Biological Sciences, School of Dentistry, Cardiff

University, Heath Park, Cardiff, CF14 4XY

*Correspondence to: Dr Paul Gill

Email:PWGill@glam.ac.uk

Refereed Paper

DOI: 10.1038/sj.bdj.2008.245

${ }^{\circledR}$ British Dental Journal 2008; 204: 371-374 particularly in dental public health, ${ }^{2,3}$ very few childhood dental studies have been conducted using qualitative research methods such as interviews. Yet research has shown that conducting qualitative interviews with children can yield rich, deep, trustworthy accounts and lead to revelations of knowledge not commonly known by adults. ${ }^{4,5}$

However, while increasing, qualitative research with children per se is still relatively rare, primarily because there are a variety of methodological, pragmatic, cognitive and ethical issues associated with interviewing minors. ${ }^{6,7}$ Consequently, children's perspectives that could be used to improve understanding and potentially influence policy, practice and future research within dentistry, are not being explored to their fullest potential. Furthermore, the paucity of existing empirical research with children also limits the scope and guidance for future research studies.

The purpose of this paper is, therefore, to explore the potential benefits of conducting qualitative interviews with children, discuss when the approach is appropriate and to offer some practical guidance on when and how to conduct research interviews with school children, based on our recent study ${ }^{8}$ in which 74 children from Years 2 (6-7 years) and 6 (10-11 years) in Cardiff, UK were interviewed about their understandings of health-related food messages.

\section{CHILDREN AND RESEARCH}

Children have traditionally been excluded from personally participating in research as they have been considered to be too immature. ${ }^{6}$ Fundamental concerns, particularly in younger children, relate to ethical issues such as vulnerability, consent and confidentiality. ${ }^{9,10}$ There are also concerns about whether children possess the appropriate cognitive, linguistic and social skills to provide adult interviewers with reliable and valid interview data. ${ }^{4,11-13}$

Whilst disciplines such as dentistry have conducted significant amounts of research involving children, the majority of data have generally not been collected directly from children themselves. Instead, an adult's (usually the mother's) opinion of the phenomenon being studied has often been sought. ${ }^{6}$ This is primarily because of the tendency to accredit adults with greater knowledge and experience than children, even in matters that affect children directly. Obviously, there are areas where a parent is better able to provide information about their child than the child is, for example in studies that require a detailed knowledge of early childhood illnesses or dental treatment.

However, there are often significant differences between parental observations about their children and the child's own perceptions. For example, when asked about children's subjective 
health, parents often portray a much 'rosier picture' of their well being than children do. ${ }^{7}$ Furthermore, older children may try to conceal certain behaviours from their parents if they think that it would invoke parental sanctions or concern. Consequently, for studies that wish to explore children's personal perspectives, proxy information is often inadequate. $^{7}$

In our study of children's understandings about food, ${ }^{8}$ parents of interview participants completed a short preinterview questionnaire, which included questions about the frequency of intake of a variety of foods. However, analysis of interview data suggested that children often made their own choices about meal composition at home and at school, and at home, often ate their meals separately from other family members. Consequently, it was difficult to link the two data sources, particularly as children indicated in interviews that their parents may not be in a position to accurately report their food intake patterns or preferences.

The problem of not involving children in research that is interested in them is that their own views and beliefs about issues that are of importance to dentistry are not properly recognised. However, the United Nations' 'Convention on the rights of the child' (1989) recommends that, wherever possible, children should be involved and consulted about all activities that affect their lives - including research. ${ }^{13}$ Consequently, the research focus has recently shifted from seeking information about children to seeking information directly from them, with most researchers generally now agreeing that the best sources of information about children are children themselves. ${ }^{4,5,11,14}$

Obviously there are a number of issues that need to be carefully considered when contemplating the appropriateness and suitability of conducting research interviews with children, such as the research question(s) and the age, gender and ethnicity of the children being studied. However, research has shown that, with the appropriate support from experienced researchers, interviews can yield detailed, reliable and trustworthy accounts from children as young as six years of age and lead to revelations of knowledge not commonly known by adults. ${ }^{4,13,15}$

\section{THE INTERVIEW FORMAT}

The semi-structured interview format (ie, where several key questions are asked that help to define the areas to be explored but also allow for divergence and/or follow up questioning) is, arguably, the most suitable for children, as it provides them with some guidance on what to talk about. Children, particularly younger children, generally find such guidance helpful in an interview situation.

\section{Pre-study preparation}

Research interviews with children are generally more manageable and cost effective in the school environment than at home ${ }^{7}$ and interviews in this setting are, therefore, the focus of this paper. Prior to conducting interviews, researchers should visit the children at their school and explain to them, in understandable language, who they are and what they are doing. This can help to establish familiarity, trust and rapport, which, subsequently, may help to promote more productive interviews. ${ }^{16}$

Researchers should carefully consider how to dress for this and any further encounters, as children may find formal attire, such as suits, intimidating and off-putting. Introductory meetings should also be used to show children any equipment, such as tape recorders, that will be used for interviewing. Children should be encouraged to ask questions, even if they are not related to the actual study, as this can also help to establish rapport. For example, in our study, ${ }^{8}$ the interviewer $(\mathrm{PG})$ was asked questions about his favourite football team and favourite animal.

When discussing the study with children it is also worth considering how much information to reveal. For example, talking to children about 'dental research' may unnecessarily influence them to think almost entirely about their teeth or related issues. Consequently, this may affect the direction and scope of any subsequent interviews, which may be particularly unhelpful in dental studies that are interested in more than just teeth, for example dental public health research.

\section{Ethical issues}

The ethical principles of research are the same, regardless of the age of the respondent, but are often more complex in studies involving children. For example, as children are legally minors, only their parents can provide their informed consent for them to participate in a study. ${ }^{10}$ However, researchers should also obtain children's assent (agreement to participate) prior to an interview commencing, as a child who does not really want to participate is unlikely to contribute to a constructive interview and may even find the process distressing, however innocuous the questions are.

Children should therefore be told, in understandable language, about the main ethical principles, such as the voluntary nature of the study, their right to withdraw at any time, confidentiality and anonymity. This explanation should also be supported by an age appropriate information leaflet. Once a verbal explanation has been given, interviewers should then establish if the child is happy to be interviewed and, of course, no pressure should be put on them to participate.

However, researchers should also be aware that, despite an explanation, some children may want to stop an interview but may feel too intimidated to do so. Even if a child fails to express their objections verbally, they may express them, more or less obviously, through their behaviour and body language, such as the tone of their voice or if they become restless and seem uneasy. ${ }^{10}$ It is therefore important to constantly observe children and consider stopping an interview if a child's behaviour changes noticeably, even if they have not said anything. ${ }^{9}$ However, reticence alone, particularly in younger children, should never be used as the sole reason for stopping a research interview, providing, of course, the child looks comfortable and relaxed.

Whilst anonymity and confidentiality are essential ethical principles that may also help to encourage honesty, they can never be absolute in research interviews, 
particularly when children are involved. Children may reveal information during an interview, such as details of abuse, that warrants disclosure to a third party, such as a parent, teacher or social services. It is therefore wise to consider, before interviewing, what issues may necessitate disclosure to a third party and how such situations should be handled.

Finally, it is also essential for all concerned that researchers working with children have the appropriate police (Criminal Records Bureau in the UK) checks before any contact is established.

\section{Interview preparation}

The environment in which interviews are conducted is extremely important to the research process and should, ideally, be quiet and free from interruptions and distractions. ${ }^{17}$ However, to ensure the safety of children and interviewers the environment should also be constantly observable. Interviews should not be conducted in private, unless another responsible adult is present. The other use of the space should also be considered. For example, while the head teachers' office may be quiet and free from distractions, its connotations as the head's office will probably remain apparent to the child and may affect their behaviour there.

Attention to the physical setting, such as seating, can help to establish a non-threatening environment where children feel comfortable. ${ }^{5}$ Therefore, if possible, comfortable chairs capable of maintaining equal eye level should be used and positioned a reasonable distance apart. The timing of interviews is also important, as this can affect how children behave. ${ }^{5}$ For example, interviewing children prior to break or lunchtime may result in less productive interviews as they may be hungry or thinking about their impending recreational time.

Quickly establishing rapport with children prior to the interview commencing is also essential, as it can help to put children at ease, improve trust and honesty, and, consequently, may lead to more constructive dialogue., ${ }^{4,715}$ It is therefore important to be friendly, informal and relaxed and to use language that is meaningful to children. Younger children may find the interview process slightly bewildering, therefore researchers should clarify the purpose of the study and what is expected from them using unambiguous and comprehensible language. ${ }^{11}$ Interviewers should also be aware that children may respond to questions regardless of whether they actually know the answer or have an opinion on the topic. ${ }^{7}$ To avoid guessing, which can affect data quality, children should therefore be told that if they are unsure about a question it is okay for them to say 'I don't know' or to ask for further clarification.

\section{The interview}

As with adult interviews, interviews with children should be recorded and transcribed verbatim to ensure a complete, accurate transcript of children's responses. However, with regards to the actual interview, younger children often find complex or hypothetical questions problematic. Interview questions should therefore be clear and unambiguous, but also capable of measuring the desired concepts. $^{5,7}$ To ensure the relevance and understandability of the interview schedule, it is prudent to pilot the interview on several children before commencing proper data collection.

Children often require far more guidance and support during interviews than adults do. ${ }^{11}$ This may simply involve clarifying or rephrasing questions if a child does not understand what they have been asked. Researchers must, therefore, be constantly aware, flexible and able to modify the interview to meet the child's developmental requirements and language levels. ${ }^{6}$ However, it is also important not to influence children's responses in any way and, as with adults, the use of 'leading' or 'loaded' questions must therefore be avoided.

Opening questions are also important to the interview process and children should be able to answer these easily, with more challenging or sensitive issues introduced later on. ${ }^{18}$ Good opening questions yield crucial data, but, in children especially, they can also help to establish rapport and the child's confidence in their ability to answer subsequent questions. In our study, 'What sort of things do you like to eat?' proved to be a productive opening question, prompting engaged, interesting and expansive answers, and also helped to develop the interviews further:

PG: 'What sorts of things do you like to eat?'

Year 6 Boy: 'I'm not a big fan on vegetables but there are a couple I like. I like peas sometimes and every so often I have carrots. And I have potatoes. I don't really like fruit, I only have bananas... but I like things like crisps, but not too often. I don't like to eat too much salt... Erm and I like eating chocolate now and then but... but there's nothing that I eat really too much.'

The introduction of sensitive or emotive topics must be approached with great caution when interviewing children. In our study, it was decided at the planning stage that the concepts of 'good', 'bad', 'healthy' or 'unhealthy' foods would not be introduced by the interviewer before the child had introduced them. This was partly to establish whether these concepts had meaning for the children without prompting, but also to avoid causing any distress or influencing the interview by being apparently judgemental about the child's eating habits. Usually children would introduce these concepts spontaneously in expected ways:

PG: 'So what do you think sweets do to your teeth then?'

Year 2 Girl: 'They can get them smaller and they can fall out.'

PG: 'Why do you think they do that?'

Year 2 Girl: 'Because they're bad for you.'

Yet other children did not raise these concepts, and to have incorporated them into questions or follow up prompts would probably have led the responses in a direction that did not reflect the thought processes of the child:

PG: 'Would your family allow you to eat it [burgers] more often?'

Year 6 Boy: '...well not really.'

PG: 'And why do you think that?'

Year 6 Boy: 'Well they'd just say oh I'm not eating that again or something likes that.'

PG: 'Why do you think they wouldn't allow you to eat it all the time?' 
Year 6 Boy: 'Because they wouldn't like to go to the same place all the time?'

PG: 'Any other reason?'

Year 6 Boy: [shakes head].

As discussed in paper two of this series, ${ }^{1}$ actively listening to what respondents say without interrupting them is an important interviewing skill, ${ }^{19}$ as it allows their accounts to develop properly and provides cues for developing the interview further. This is particularly important when interviewing children as they often require longer to formulate their answers than adults do. ${ }^{15}$ Children may also find unnecessary interruptions distracting and confusing, which may ultimately result in the collection of incomplete or inaccurate data. Children should therefore be given sufficient time to answer questions and, if they say something that warrants further elaboration, interviewers should wait for a suitable pause before following up the issue further. If, after a reasonable amount of time (at least several seconds), a child is clearly struggling to answer a question, it may be worthwhile rephrasing or re-clarifying the question for them.

As with adult interviews, the use of good interviewing and interpersonal skills can help to ensure that interviews with children are as productive as possible, for example, looking interested, smiling, nodding and asking appropriate follow-up questions. ${ }^{18,19}$ The strategic use of silence can also be highly effective in eliciting more information, as it allows children sufficient time to think about their answers before responding. However, if it becomes apparent during a break in the conversation that a child appears to be confused or bewildered, then the use of silent pauses may be ineffective and perhaps even counterproductive. Silent pauses should, therefore, be used carefully and appropriately and interviewers should intervene after a suitable period has elapsed, especially if the child looks perplexed, by rephrasing or re-clarifying a question.

Interviewers also need to be aware that children, like adults, may deliberately withhold information if they think that it may elicit a negative response from the interviewer. ${ }^{11}$ In order to obtain full, accurate and honest accounts, it is important to avoid looking shocked or expressing disappointment at anything a child says during an interview.

The use of visual props, such as food cards, can also be an effective way of engaging or stimulating shy or reticent children, particularly younger children, during an interview. ${ }^{15,20}$ For example, if an interview is particularly unproductive despite the interviewer's best efforts, a child could arrange such cards into foods that they like and dislike, which may, subsequently, help to stimulate further conversation. However, visual aids should also be used cautiously as they can influence responses and limit the direction and quality of the interview.

At the end of an interview children should be thanked for their time and asked if there is anything further that they would like to add. This gives them an opportunity to talk about things that they think are important to the study but have not yet been raised during the interview. Brief understandable feedback about the study should also be provided, for example, that you may come back to the school at a later date to speak to everyone about the study findings.

\section{CONCLUSION}

The research interview is a valuable research method instudies involving children. Our experience, and that of many other authors (eg Mayall ${ }^{4}$ and Docherty and Sandelowski ${ }^{11}$ ), is that interviewing children can produce unique, detailed, personal accounts, which can be used to improve our knowledge and understanding on a variety of issues that are of interest and importance to dentistry. However, to ensure that interviews involving children are constructive and methodologically rigorous it is essential that researchers using this method of data collection have the appropriate training, experience and expertise.

1. Gill P, Stewart K, Treasure E, Chadwick B. Methods of data collection in qualitative research: interviews and focus groups. Br Dent J 2008; 204: 291-295.

2. Blinkhorn A S, Leathar D S, Kay E J. An assessment of the value of quantitative and qualitative data collection techniques. Community Dent Health 1989; $6:$ : 147-151.

3. Watt R. Introduction. In Fuller S S, Watt R (eds) Using qualitative and quantitative research to promote oral health. pp 1-2. Manchester: Eden Bianchi Press, 1992.

4. Mayall B. Conversations with children. In Christensen $\mathrm{P}$, James A (eds) Research with children. pp 120-135. London: Falmer Press, 2000.

5. Instone S L. Development strategies for interviewing children. J Pediatr Health Care 2002; 16: 304-305.

6. Deatrick J A, Faux S A. Conducting qualitative studies with children and adolescents. In Morse J M (ed) Qualitative nursing research. pp 203-223. Newbury Park: Sage Publications, 1991.

7. Scott J. Children as respondents. In Christensen $\mathrm{P}$, James A (eds) Research with children. pp 98-119. London: Falmer Press, 2000.

8. Stewart K F, Gill P, Treasure E, Chadwick B. Understandings about food among 6-11 year olds in South Wales. Food Cult Soc 2006; 9: 317-333.

9. Alderson P. Ethics. In Fraser S, Lewis V, Ding $S$, Kellett M, Robinson C (eds) Doing research with children and young people. pp 97-112. London: Sage Publications, 2004.

10. Helseth $S$, Slettebo A. Research involving children: some ethical issues. Nurs Ethics 2004; 11: 298-307.

11. Docherty S, Sandelowski M. Focus on qualitative methods: interviewing children. Res Nurs Health 1999; 22: 177-185.

12. Domel S B. Self reports of diet: how children remember what they have eaten. Am J Clin Nutr 1997; 65 (Suppl): 1148S-1152S.

13. Robinson C, Kellett M. Power. In Fraser S, Lewis V Ding S, Kellett M, Robinson C (eds) Doing research with children and young people. pp 81-96. London: Sage Publications, 2004.

14. Lewis $V$. The reality of research: an introduction. In Lewis V, Kellett M, Robinson C, Fraser S, Ding S (eds) The reality of research with children and young people. pp 1-4. London: Sage Publications, 2004.

15. Kellett M, Ding S. Middle childhood. In Fraser S, Lewis V, Ding S, Kellett M, Robinson C (eds) Doing research with children and young people. pp 161174. London: Sage Publications, 2004.

16. Aldgate J, Bradley M. Children's experience of short term accommodation. In Lewis V, Kellett M, Robinson C. Fraser S, Ding S (eds) The reality of research with children and young people. pp 67-93. London: Sage Publications, 2004.

17. Pontin D. Interview. In Cormack D F S (ed) The research process in nursing. 4th ed. pp 289-298. Oxford: Blackwell Science, 2000.

18. Britten N. Qualitative interviews in healthcare. In Pope C, Mays N (eds) Qualitative research in health care. 2nd ed. pp 11-19. London: BMJ Books, 1999.

19. Kvale S. Interviews. Thousand Oaks: Sage Publications, 1996.

20. Mauthner M. Methodological aspects of collecting data from children: lessons from three research projects. Child Soc 1997; 11: 16-28. 